\title{
Improved building sustainability in seismic zones
}

\author{
Sustentabilidad mejorada de edificaciones en zonas sísmicas
}

\section{Ricardo E. Arriagada D.}

Independent Consultant in Constructability, DICTUC S.A.

Santiago (Chile)

rarriaga@uc.cl

\author{
Manuscript Code: 1154 \\ Date of Acceptance/Reception: 04.04.2019/19.07.2018 \\ DOI: $10.7764 /$ RDLC.18.1.167
}

\begin{abstract}
Construction worldwide is under great pressure to generate significant changes in the sector. A significant change requires a multidimensional vision that integrates different perspectives, promoting a deep knowledge of the constructive process and it's parallel with manufacturing as a comparative basis. For the specific case of the construction of reinforced concrete in seismic zones, it is proposed to move from the division of labor by specialties to the division of labor by spatial volumes, which considers the functional and systemic perspectives. This is proposed in order to characterize the life cycles of the different systems within a building, guaranteeing a high level of sustainability. To achieve this objective, a real high-rise building project with its respective BIM model will be used as a basis for the construction of another twin BIM model (mirror) that will use design criteria that meet the objectives of this proposal. It will use the original model data and the information obtained from the monitoring of the project execution phase. This proposal will present, in a comparative way, this strategy's impact on the design and execution of the real project in which the installations are completely disincorporated from the structure, emulating the simile of an assembly line. It is expected that the results will demonstrate that an evident improvement in sustainability is achieved by making the different systems of a building independent, allowing the life cycle of each system to maximized. This independence, in turn, generates the conditions for a substantial improvement in productivity. On the other hand, the integration of engineering with the construction of functional solutions off-site allows for a significant improvement in constructability, in addition to externalities that can only be characterized in the exploitation phase. This will allow a radical change in the supply market, transferring an important amount of knowledge towards the sector. This experience will generate outstanding leadership in the sector and a categorical emphasis in the direction of innovation.
\end{abstract}

Keywords: Building height, life cycles, BIM model, sustainability, productivity, constructability, innovation.

\begin{abstract}
Resumen
La construcción en todo el mundo está bajo una gran presión para generar cambios significativos en el sector. Un cambio significativo requiere una visión multidimensional que integre diferentes perspectivas, promoviendo un conocimiento profundo del proceso constructivo y su paralelo con la manufactura, como base comparativa. Para el caso específico de la construcción de concreto reforzado en zonas sísmicas, se propone pasar de la división del trabajo por especialidades a la división del trabajo por volúmenes espaciales, que considere las perspectivas funcionales y sistémicas. Esto se propone para caracterizar los ciclos de vida de los diferentes sistemas dentro de un edificio, garantizando un alto nivel de sostenibilidad. Para lograr este objetivo, se utilizará un proyecto de edificación en altura real con su modelo BIM respectivo, como base para la construcción de otro modelo BIM doble (espejo) que usará criterios de diseño que cumplan con los objetivos de esta propuesta. Utilizará los datos del modelo original y la información obtenida del monitoreo de la fase de ejecución del proyecto. Esta propuesta presentará, de manera comparativa, el impacto de esta estrategia en el diseño y la ejecución del proyecto real en el que las instalaciones serán completamente desincorporadas a la estructura, emulando el símil de una línea de ensamblaje. Se espera que los resultados demuestren que se logra una mejora evidente en la sostenibilidad al hacer que los diferentes sistemas de un edificio sean independientes, lo que permite maximizar el ciclo de vida de cada sistema. Esta independencia, a su vez, genera las condiciones para una mejora sustancial en la productividad. Por otro lado, la integración de la ingeniería con la construcción de soluciones funcionales fuera del sitio, permitirán una mejora significativa en la capacidad de construcción, además de las externalidades que solo se pueden caracterizar en la fase de explotación. Esto permitirá un cambio radical en el mercado de suministro, transfiriendo una cantidad importante de conocimiento hacia el sector. Esta experiencia generará un liderazgo sobresaliente en el
\end{abstract} sector y un énfasis categórico en la dirección de la innovación.

Palabras clave: Edificación en altura, ciclo de vida, modelo BIM, sustentabilidad, productividad, constructabilidad, innovación.

Introduction

Currently, construction worldwide is under great pressure to generate significant changes in the sector. The main areas that advocate change include: manufacturing, particularly with the significant achievements in prefabrication, modularization and industrialization in the industries of automobiles, airplanes and ships; in the development, interpretation and application of production theories, such as construction without losses (Lean Construction) and the open building system (Open Building System), which focus on the generation of value for the client, elimination of losses, and on a transversal systemic vision that transits from the macro to the micro; and in sustainability, which deals with identifying the environmental impact of the entire building cycle and the mitigation mechanisms, resulting in a macro-systemic perspective.

By integrating the previous views, it is possible to imagine a building from five perspectives and/or dimensions. The first dimension is the disciplinary perspective, which is related to the areas of knowledge that currently dominate 
the design and construction processes. The second dimension is the geometric-spatial perspective, which is related to spatial volumes and their vicinity, which has become standard in BIM solutions. The third is the functionaloperational perspective, which is related to the activities, uses and/or functions established for each environment. The fourth dimension is governed by a systemic perspective, in which the systems, subsystems and associated life cycles determine the border, independence and flexibility criteria of each system and subsystem. The fifth dimension, which is transversal to the four previous perspectives, is the sustainability perspective.

\section{The disciplinary perspective}

The industrial revolution advocated the division of labor as the central axis of efficiency and specialization, a necessary pillar for productivity. Nowadays, the division of labor and specialization in the construction sector is more evident than in any other production area, since its processes occur in the field and in the view of the community. The natural division of labor that exists in a construction project requires dividing the total scope of the project among the individuals and groups that will participate in it. The division of labor is necessary when the scope of work exceeds what a single person can complete within the established time frame, or when there is not a single person who can master all the knowledge and skills required by the project. However, the benefits of the division of labor are not free since it entails a risk associated with the integration of information, knowledge, and deliverables, which make up the final product. This integration is where the greatest problems and losses of productivity are concentrated.

Figure 1 shows this perspective in which the knowledge areas, their sequence, and their integration and coordination in the design phase become evident. Given the mechanisms and bidding practices, the contractor operates both as a counterpart of the design and as a builder.

Figure 1. The disciplinary perspective. Source: Self-Elaboration.

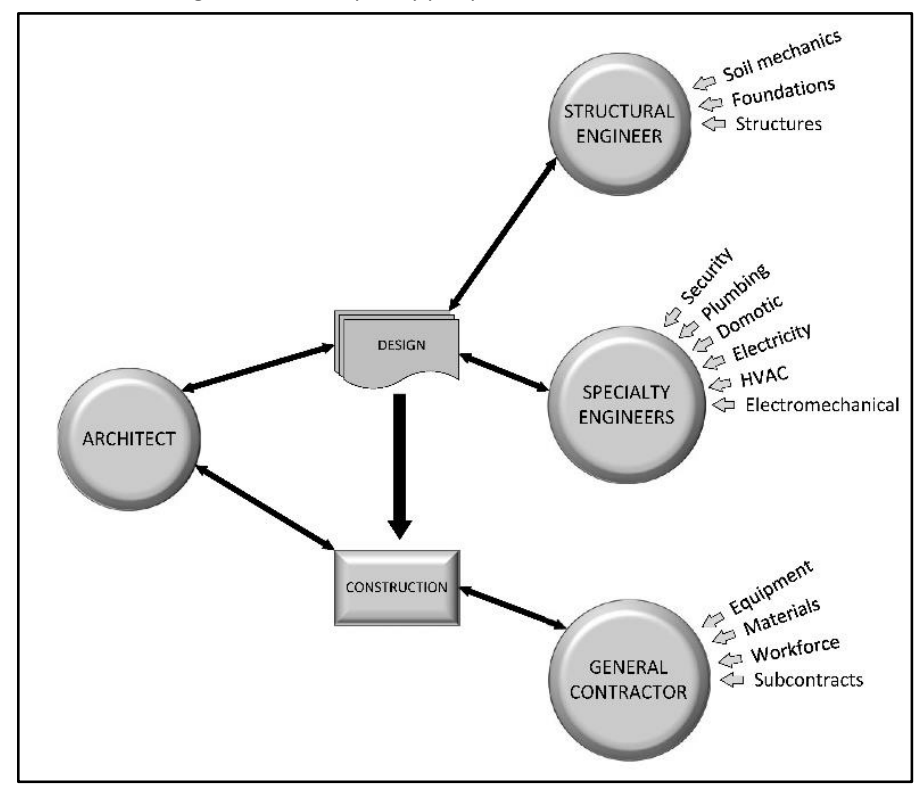

\section{The geometric-spatial perspective}

The digital integration of databases with graphical interfaces in the design stage gave rise to a new perspective in which transverse knowledge is represented and coordinated graphically, generating volumetric solutions and characterizing adjacencies. This scenario generally occurs at an intermediate stage between design and construction, which is usually called modeling.

As in the past, a successful work plan is used as a template for similar works, in which the tested solutions were reproduced. At present, a geometric-spatial solution is a proven volumetric solution in which you can reproduce a template for a new, similar proposal. A Building Information Model (BIM) characterizes geometry, spatial relationships, geographic information, quantities and properties of building elements, cost estimates, material inventories and the project schedule. The model can also be used to analyze the life cycle of the building and its constituents. 
Figure 2 shows a graphical representation of this perspective, in which the BIM model is the great articulator of the different specialties, guaranteeing an optimal Constructability by integrating the Contractor in the later stages of the design, and in the early stages of construction.

Figure 2. The geometric-spatial perspective. Source: Self-Elaboration.

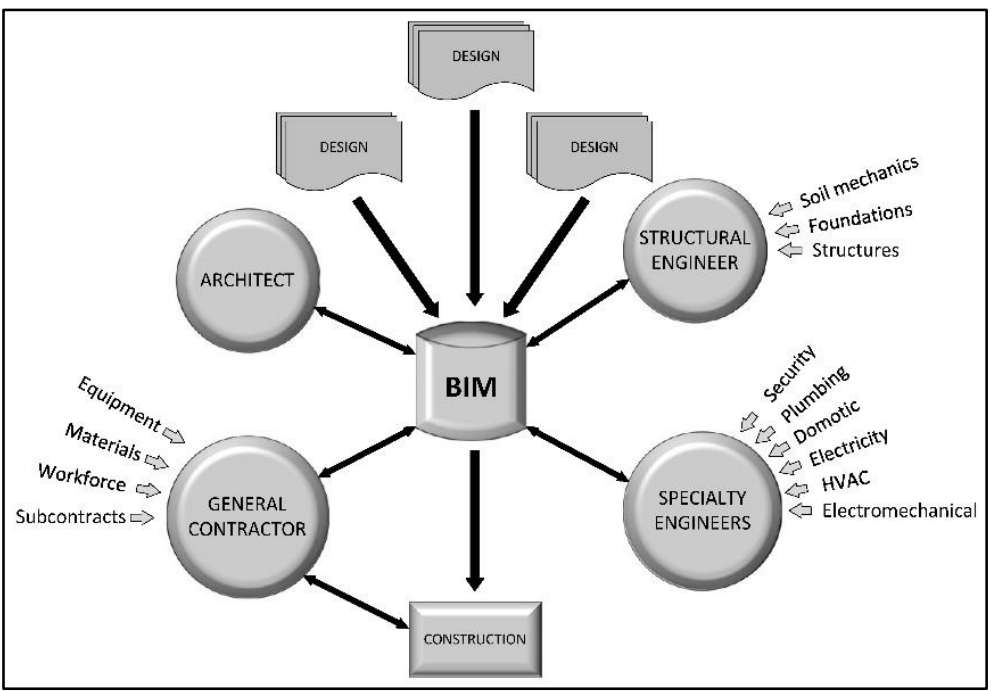

\section{The functional-operational perspective}

Generally, every building fulfills a purpose and/or satisfies a need. In both scenarios, these purposes and/or needs are disaggregated into discrete temporal events that generate environments with activities and/or limited uses, whose vicinity is determined according to sequences and precedence. In the case of Facilities (hospitals, schools, stadiums, barracks, prisons, etc.), this perspective acquires its greatest value, since it is common practice to generate a technical sheet with all the specialty requirements of each of the spaces according to its use and with attention to the applicable regulatory bodies and the scope of the design proposal (Binggeli, 2016, Buxton, 2015; Moscow, 2012, \& Lee, 1997). Taking the case of multi-family dwellings as an example, the environments can be grouped into three levels: family unitary, collective family, and services.

Figure 3 presents a schematic approach to design in which there is a marked separation between the structure (support) and the functional volumes (infill). Specialist engineers must coordinate in advance to find the optimal solutions for each type of use to ensure a high degree of Constructability. The coordination of specialties outside the spaces with specific uses is handled by a different individual. This perspective can be considered as a transition between the geometric-spatial perspective and the systemic perspective.

Figure 3. The functional-operational perspective. Source: Self-Elaboration.

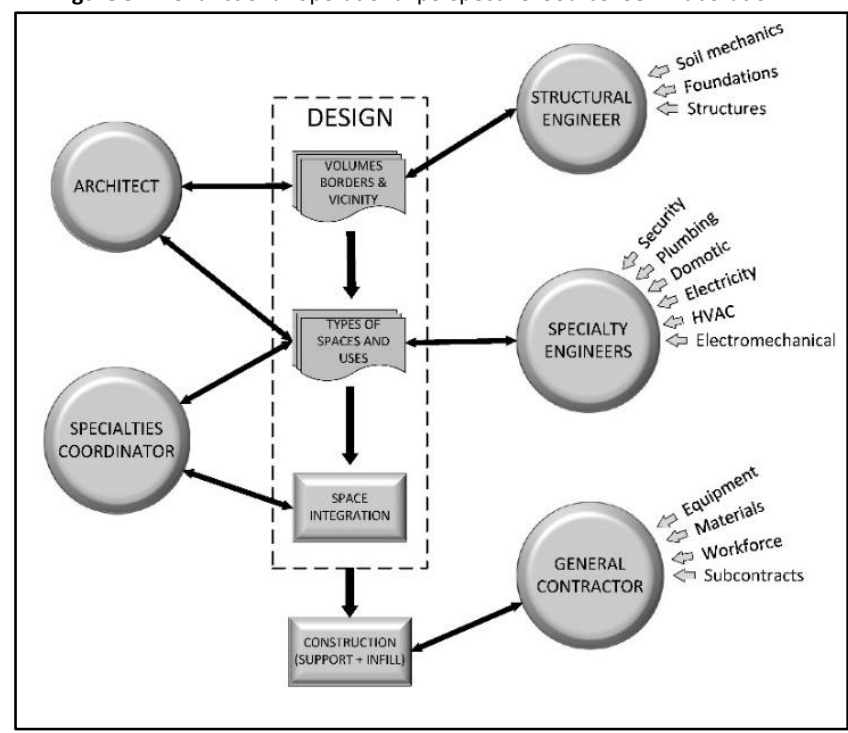




\section{The systemic perspective}

This perspective had its first expressions with Habraken (1961), who suggested identifying different decision levels in order to uncouple parts of a building with different life cycles. In this perspective, each part is controlled by different specialists in order to resolve the conflict between the inertia of the building and the construction industry. $\mathrm{He}$ is recognized as one of the promoters of the open building system (Open Building System OBS).

\begin{tabular}{llc}
\multicolumn{3}{c}{ Table 1. Typical life cycle in a building. Source: Self-Elaboration. } \\
\hline \multicolumn{1}{c}{ Systems } & \multicolumn{1}{c}{ Component } & Life cycle (years) \\
\hline Structure & Foundations and loading elements & 40 to 60 \\
Roofs and facades & Roofs and exterior cladding & 15 to 20 \\
Services & Major equipment (elevators, water pumps, ponds, etc.) & 12 to 18 \\
& Distribution networks (conduits, pipes, cables, etc.) & 10 to 15 \\
& Minor equipment (bathrooms, kitchens, etc.) & 7 to 12 \\
Interior spaces & Partitions and internal divisions non-structural & 5 to 10 \\
& Terminations (paper, paint, plasters, etc.) & 3 to 5 \\
\hline
\end{tabular}

In Figure 4 it can be seen that the emphasis on design is located in the concept of a system linked to the "macro functions and/or macro services" as an evolutionary perspective from the volumetrics and their uses. There are two central ideas in this perspective; the first is the physical independence (rather than functional independence) of each system, since all systems must work in coordination; second, that each system has a projected life expectancy, in which each of the sub-systems that compose it have a limited useful life (sanitary ware, kitchens, heaters, boilers, exchangers, etc.), which is usually recommended by its manufacturers and constitute the minor and major teams of the system (Durmisevic \& van lersel, 2003).

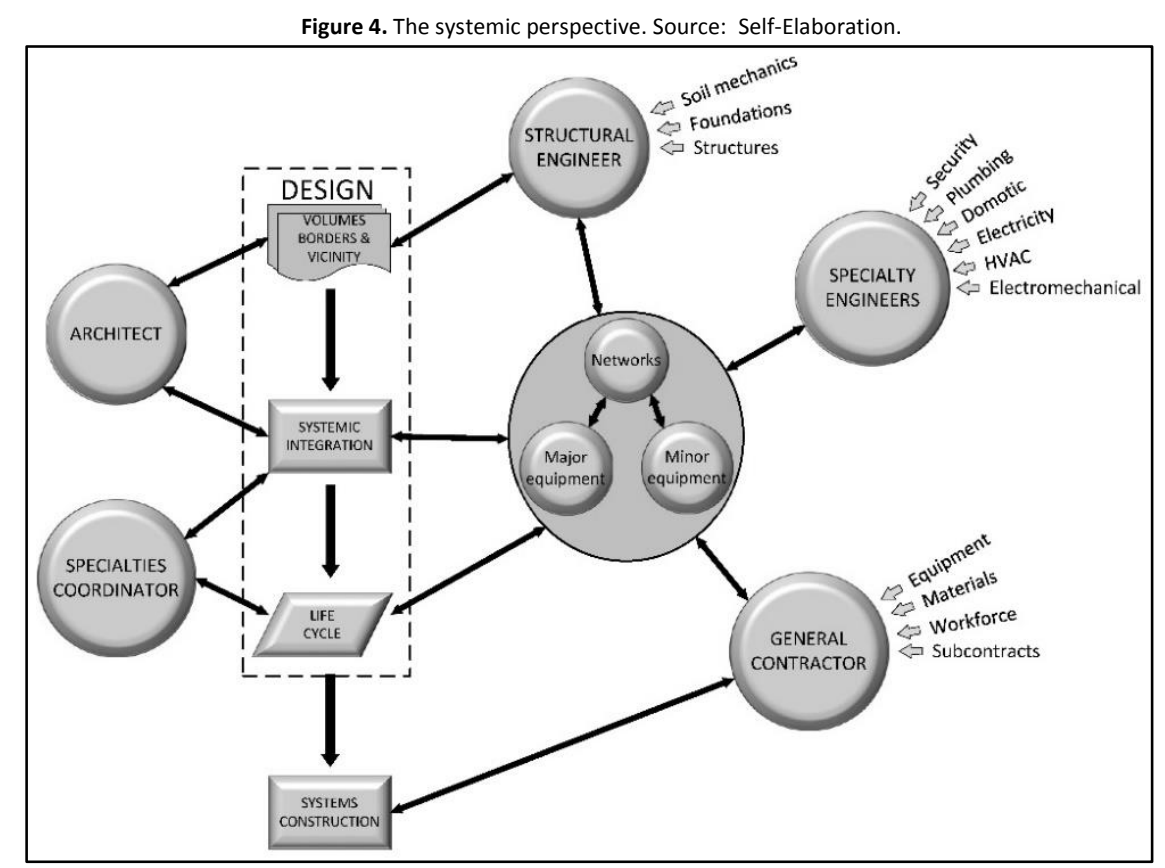

\section{The sustainability perspective}

The definition of sustainability that has been generally accepted in the context of human beings who are interested in building and living in a more "sustainable" world was initially developed in the World Commission on Environment and Development (WCED) in 1987. Their manifesto states that "sustainable development is one that meets the needs of the present, without compromising the ability of future generations to meet their own needs".

Sustainable construction is a subset of sustainability in general, which focuses more on the construction of the environment, both during the construction phase and the operational life cycle of the facility. However, both sustainability and sustainable construction are subject to interpretation and are very difficult to define. What may seem sustainable in one culture, or by one set of values, may not seem sustainable to another. Likewise, the concepts that can be seen as more important for sustainability by some people may not be as important for others (Haselbach, 2010). 
Sustainable construction has three large areas: the environment, which is interested in the creation of structures that use resources efficiently and processes that are environmentally responsible throughout the life of the building; the economic, intimately linked with the environmental perspective in the efficient use of resources and the elimination of losses; and the social area, interested in the protection of life and the well-being of people throughout the life cycle of the building. According to Siew Goh \& Rowlinson (2013), the main variables for evaluating sustainability in construction are the following:

Table 2. Main and secondary factors in sustainable construction. Source: Siew Goh \& Rowlinson (2013).

\begin{tabular}{|c|c|}
\hline Main Factors & Secondary factors \\
\hline $\begin{array}{l}\text { 1. Consumption of resources } \\
\text { and materials }\end{array}$ & $\begin{array}{l}\text { a. Recycling and reuse of materials and water } \\
\text { b. Efficiency in the use of resources } \\
\text { c. Land use }\end{array}$ \\
\hline 2. Environmental impact & $\begin{array}{l}\text { a. Waste management } \\
\text { b. Elimination of toxic } \\
\text { c. Carbon emissions } \\
\text { d. Ecosystem } \\
\text { e. Efficiency in the use of water }\end{array}$ \\
\hline 3. Comfort quality & $\begin{array}{l}\text { a. Occupational health and safety } \\
\text { b. Quality of the interior environment (air, noise, lighting, ventilation, } \\
\text { temperature and humidity) } \\
\text { c. Control of chemical sources and indoor pollutants } \\
\text { d. Systems controllability (lighting, temperature, ventilation. etc.) } \\
\text { e. Satisfaction of occupants and owners }\end{array}$ \\
\hline 4. Energy efficiency & $\begin{array}{l}\text { a. Renewable energies (biomass, wind energy, solar energy, etc.) } \\
\text { b. Optimal energy performance }\end{array}$ \\
\hline 5. Design process & $\begin{array}{l}\text { a. Natural light } \\
\text { b. Thermal comfort } \\
\text { c. Ventilation } \\
\text { d. Flexibility and adaptability of spaces } \\
\text { e. Ecological innovation }\end{array}$ \\
\hline 6. Calculation of the life cycle & $\begin{array}{l}\text { a. Cost effectiveness } \\
\text { b. Financial return } \\
\text { c. Periods of recovery }\end{array}$ \\
\hline 7. Functional applicability & a. Market demand and supply \\
\hline 8. Life expectancy & $\begin{array}{l}\text { a. Lifespan / durability of the construction and design } \\
\text { b. Maintenance and renovation }\end{array}$ \\
\hline $\begin{array}{l}\text { 9. Heritage and cultural } \\
\text { preservation }\end{array}$ & $\begin{array}{l}\text { a. Preservation of the inheritance } \\
\text { b. Preservation of culture }\end{array}$ \\
\hline
\end{tabular}

Figure 5 presents a summary of the sustainable life cycle of the building, in which the design phase is key to move towards a sustainable cycle in the construction sector.

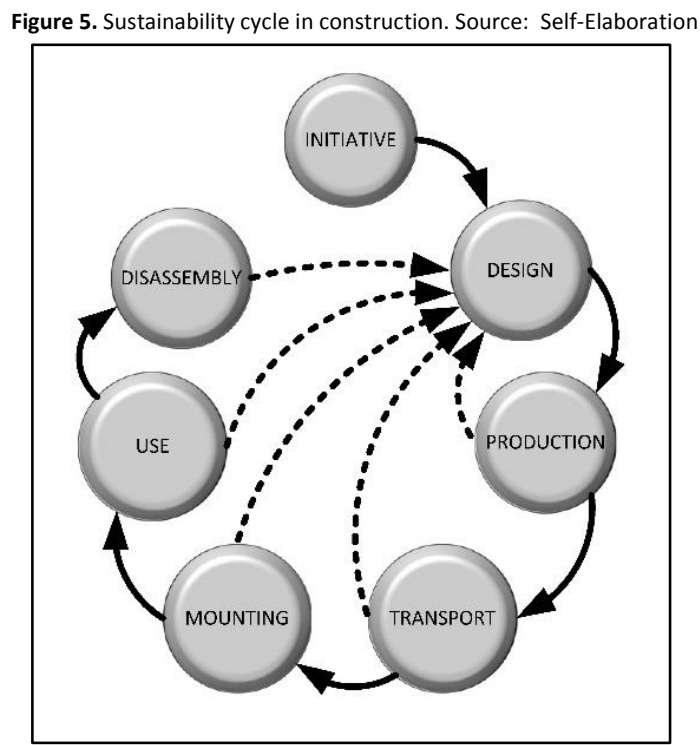


Some of the main sustainability strategies include: reducing losses, reducing energy consumption, increasing recycling, increasing reuse, and increasing the life cycle of the building (CIB, 2010).

\section{Presence of these perspectives in the construction sector}

At present, it is very difficult to accurately characterize the current state of innovations in the global construction sector. It can only be asserted, with some degree of certainty, that the main proposals are located in interpreting and reproducing the main achievements of the manufacturing sector (automobiles, ships and aircraft) through standardization, modularization, pre-assembly, deconstruction, IFD (Industrial, Flexible and Demountable Building) and industrialization; moving from on-site construction to off-site construction; and from classic to collaborative contracting, in which risks and achievements are shared (IPD Integrated Project Delivery) (McKinsey, 2017; Green, 2016; Emmit \& Gorse, 2014; CIB, 2012, 2013 \& 2014; Smith, 2010; Kazi et al., 2009; Halliday, 2008; and many others). In the case of Chile, the perspective that governs the constructive process is the disciplinary perspective.

\section{Description of the Problem}

Chile is one of the many areas in the world considered "seismic". In the last sixty years, it has suffered the consequences of several earthquakes with intensities higher than $7.5 \mathrm{Mw}$. Currently, and according to the regulatory bodies and the best cost-structural solution, more than $77 \%$ of high-rise buildings are built using the technique of reinforced concrete cutting walls. Most of them are for residential use and use a "classic" configuration for each level of the building, called "fishbone". This consists of a pair of longitudinal walls that make up the central corridor of the level, and a series of transversal walls of equal constitution. (Vásquez, 2015; Jünemann, 2016).

Japan is another country with similar seismic conditions that prefers to use the same structural solutions for its highrise buildings, and particularly those of multifamily housing. Unlike Chile, by 1970, Japan had begun to introduce varied proposals for high-rise multi-family dwellings in urban developments. These proposals continued the concepts of "support" (structure) and "infill" (filling), which dominated those which were physically separated, but not separated at the level of management or decision-making. By the 90s this proposal had evolved and generated great flexibility, thus establishing the concept of the "Open Building System" (Open Building System) (Fukao, 2009).

From the perspective of sustainability, the concept of the OBS (Open Building System) in Japan is fundamentally oriented to identify and make the different life cycles of systems and sub-systems that compose multifamily housing construction independent and flexible. This has given birth to the concept "SI house" (Skelton Infill house) (Fukao, 2009).

It is important to keep in mind that "useful life" is defined as the period between the construction of a building and the moment when the building, or a part of it, loses structural security, functional habitability, visual aesthetics, and / or the economic cycle. If a building does not have adequate independence between the systems and sub-systems that compose it, there is a risk that a system with a shorter life cycle will limit a system with a longer life cycle.

Okamoto \& others (2000) have taken advantage of this independence to maximize the life cycle of the structural system within the perspective of the OBS. They formulated a concrete composition and a structural design that they use as a model to analyze their behavior for a 200 -year life cycle in a highly seismic zone (Kanto).

In Chile, construction companies are at a very early stage in sustainable construction. Since there are no local regulations, the level of innovation in the sector is small and there are no local stimuli to encourage advancements. Additionally, there is a generalized opinion that innovation and sustainability entail an additional cost. According to Serpell et al. (2013), the main barriers to sustainability in the Chilean sector are the lack of financial incentives, the lack of integrated design, and the lack of government policies.

In Chile, the "disciplinary perspective" of building construction is preferred for dividing the work into "specialties" by executing them completely "on-site" with a reduced component of modularity. The reinforced concrete structure is completely executed on the construction site, a dynamic that governs the rest of the specialties. The systems and subsystems are interwoven with "null independence", an example of which are the MEP (Mechanical, Electrical and Plumbing) installations that are embedded in structural walls, slabs and partitions. 
The main objective of this proposal is to improve the sustainability of reinforced concrete buildings in seismic zones by intervening in the design criteria of the specialties. This is necessary in order to identify and categorize the life cycles of the different systems within the buildings. A secondary objective is the identification of the potential impact that this independence generates on productivity in both the design and construction phase of a building.

The tertiary set of objectives is difficult to achieve, since they are linked to the exploitation and demolition phase of the building and are associated with the levels of independence, coordination and inter-system flexibility that the design provides. In the case of exploitation, they facilitate the operations of repair, maintenance, updating and renewal of the different systems, at reasonable costs. They are also supported by a high degree of modularity and dismantling of the system elements. In the case of demolition, the life cycle of the constituents, their recovery and partial reuse are considered highly viable, given that they would maintain their identity and unitary functionality during their respective lives. The identification of the different life cycles will allow the development of proposals to maximize some cycles and to level others.

\section{Development of the proposal}

In order to fulfill the above objective, a conceptual transition from the division of labor by specialties to a division of labor by spatial volumes which considers the functional and systemic perspectives is proposed. If a parallel is made with the construction of cars it should be remembered that the first element that enters the assembly line is the structure (frame and/or chassis), forming large spaces and/or cavities. When this structure advances in the line, the different systems that compose it are incorporated under an ordered volumetric hierarchy, which in turn generates smaller spatial volumes. If the attention is focused on the motor system, the first thing that is incorporated into the structure is the motor with the gearbox, followed by the HVAC systems, steering, power generation, brakes, transmission, cooling, power supply, fuel system, etc. Finally, the cable bundles and hoses that connect all the systems are incorporated. Something very similar happens with the cabin.

In the case of a reinforced concrete building, the starting point is complete disincorporation of the MEP installations of the structure. This generates the need to reformulate the design criteria, placing the emphasis on pre-design. On the other hand, the structure can be optimized, since reinforcing steel does not have to compete with embedded installations, and from the perspective of the construction process, the structure can acquire an optimum "takttime" (productive rhythm).

In the first stage of the construction that constitutes the reinforced concrete structure, the spatial volumes that will give rise to the different spaces with their associated uses are generated. Supported by the principles of the OBS (Open Building System), the installations vertically accompany the structure based on the normative definitions associated with the specific uses. These uses are equivalent, on the one hand, to establish for each volume, according to its use, the parameters of the specific details engineering, and on the other, to dimension the general networks of the installation systems in the global detail engineering. The global detail engineering conditions the specific details engineering.

Returning to the car assembly analogy, the starter motor has a clearly defined space next to the flywheel of the engine (larger rear gear) in the lower area. The specialties of cast iron (carcass), mechanized (fields and rotors), electricity (winding, delgas and carbons), electronics (thermistors, limiters), etc., converge in the starter motor, which enters the assembly line as an externally manufactured element that incorporates detail engineering and construction based on conceptual definitions associated with the receiver element. These definitions are the pitch of the steering gear, the torque at minimum revolutions to produce the ignition of the engine, the minimum revolutions to activate the centrifugal release system, the caliber of the electric conductors to feed in $12 \mathrm{Vdc}$, and the capacity of the battery to supply the starting current.

In the case of a building, if a bathroom is taken as an example, it will normatively have a limited volume, with a floor area that will contain the sanitary appliances. Conceptually, the architect will determine if the bathroom will have natural or artificial ventilation, the quantity and type of artifacts, as well as the possible configurations that can be adopted in the plant. For its part, the sanitary engineer will determine the mechanical ventilation if it is a Mediterranean bath, and the units of expenditure and discharge required by the sanitary devices. The electrical engineer will determine the maximum electrical power installed in the enclosure, according to the type of artifacts to be used in that environment, the recommendations regarding the wet areas and lighting levels, as well as the 
minimum luminous efficiency. Finally, the HVAC specialist will determine the minimum energy required to heat that environment, the recommended medium and the temperature control mechanism.

The total set of demands for building installations is the sum of the demands of each environment that constitute the collective networks of the installation systems, both specific and global, as well as the analysis of contemporaneity. This means that as the structure progresses, the reserves and spaces through which the networks of the installations will transit will be generated in the common sectors of the building. Unlike the assembly line of a car, the demands of the peripheral volumes of a building determine the capabilities of the central networks of said building. In the case of a car, the power plant determines the characteristics of the peripherals.

In accordance with the above, the essence of the proposal is to completely separate the structure of a reinforced concrete building from its installations. This generates two significant scenarios: the first, an uninterrupted flow of embankments, moldings, shoring and concrete castings, ensuring a single actor on the site of the work; the second, a previously designed set of routes, spaces and cavities that will house the networks of installations next to the provisions of the major and minor equipment. These networks will be dimensioned by the demands in the different disciplines of the volumes served and according to their use. This is how the diameters of the sewage discharges, sanitary vents, water mounts, the section of the air injection and extraction ducts, and the diameters and the gauges of the electric feeders, etc. will be known, prior to the details engineering specific to the interior of the different environments.

At this level of decisions, the scenario resembles that of a car, since the networks of the installations of the different specialties become the regulating factor of the development of the details engineering of the different volumes and their associated uses. These regulations are expressed in geometric restrictions, plant configurations, installed capacities, etc.

It can be seen that the installations operate in two separate temporal stages; the first, in which the global network of systems that constitute the building installations are installed according to the spaces and cavities generated by the structure; and the second, which represents the spatial volumes, will include in their spatial borders the intakes, discharges and connection points established for each environment according to their use, once the structure is completed.

In the previous scenario there are two alternatives: first, that the spatial volume hosts a sub-set prepared off-site which connects with the global network to form a unitary team; second, that the sub-set be armed on-site so that it also connects to the previously installed global network as a solution to arm, rather than as a unitary team. In both cases, the strategy of the car's starter engine will be followed; integrating details and construction engineering and coordinating with the interfaces of the respective systems located at the borders of the spatial volume, according to the type of use.

Given the temporary pause that exists between the execution of the installations, it is possible to delay and personalize many decisions associated with the spatial volumes and their associated uses, either by the acquisition of more certainty, or by satisfying the specific requirements of a client. The idea is that the set of subsets of a specific system is produced by the same contractor. For example, the general contractor will stop buying sanitary appliances and their accessories. Instead, he will buy bathrooms installed with their respective appliances, accessories and coatings.

It is proposed to develop the present proposal at the level of computational modeling, in which, from the design phase a real project, it is possible to build a twin model (mirror) developed under the previous concepts. This endeavor necessitates the interest and support of a company, the owner of the model project, and an interest in innovation. The idea is to have access to the team of designers, the BIM model and the execution plan to physically track the construction of the project to its conclusion. In this relationship, it will be possible to quantify the key variables that will feed the original BIM model and the twin (mirror) developed under this proposal. Both projects will be based on the same values (times, costs, scopes, and productivities) in order to observe the immediate comparative benefits.

The BIM model, twin to the project (mirror), will surely contain some changes that will not modify the essence the original project. However, at the design level the changes will be necessary to carry out the conceptual proposal. It must be acknowledged that this proposal has a long-term objective associated with the life cycle maximization of the of the main building systems and the use of its constituents, which from a business perspective is difficult to 
account for in present value. For this reason, modeling would allow the observation of some short-term benefit that may be the trigger for its physical implementation.

Figure 6 graphically represents the methodological proposal in which the design of specialties and the pre-assembly occur off-site for subsequent on-site assembly, according to the rate at which the reinforced concrete structure is being built. The first assemblies correspond to the different networks; then the major equipment follows; and finally, the minor equipment finish the details.

Figure 6. Graphic representation of the proposal. Source: Self-Elaboration.

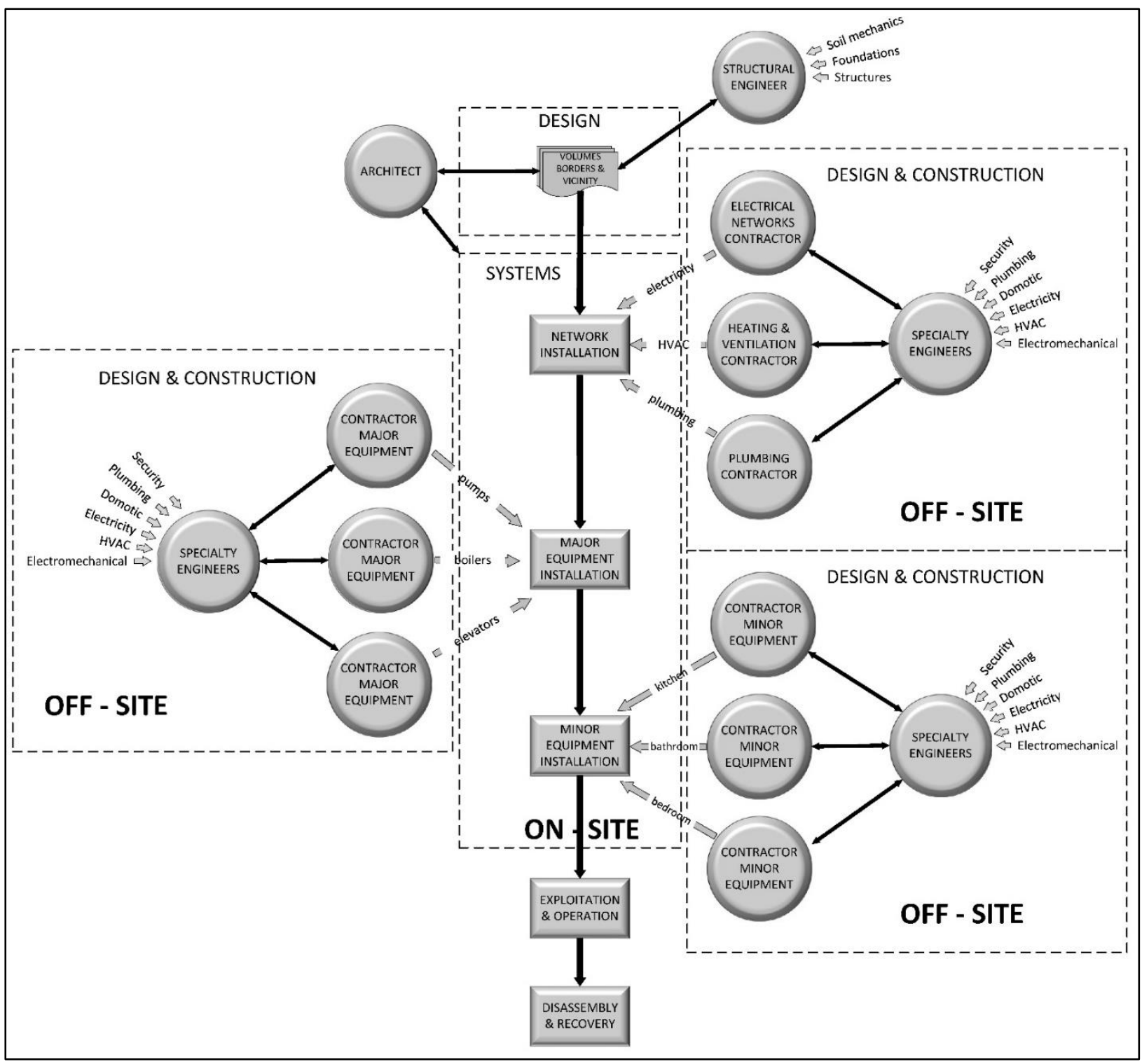

The expected results involve two temporal instances. The first is associated with the comparative analysis of the values acquired by the variables provided by the two BIM models and includes the physical follow-up of the work under study and the impacts of changing the assignment order over time for a set of activities. The second is associated with the impacts of the exploitation and demolition phases of the systems and sub-systems present in the building.

From the comparative analysis of the values of the variables generated by the models, a potential increase in the life cycle of the structure is expected. Additionally, a significant reduction in the construction time of the reinforced concrete structure is expected by eliminating waiting times generated by the inlay of the installations in the structure and by having only one actor. The above generates many opportunities to innovate in shoring techniques, the casting 
of concrete of the type of formwork to improve the completion of clean work, and the improvement of the concrete mix.

On the other hand, the forced integration of engineering and off-site construction shifts an important amount of engineering hours to the constructor-provider of functional solutions. This transfer generates optimal conditions for learning, thanks to the iteration of the solutions that was originally modeled by the manufacturing industry. This transfer allows for the acquisition of the optimal construction for each of the functional solutions. As a result of this learning, a significant reduction in the cost over time for these functional solutions is highly probable.

The impacts of difficult sizing in this proposal are mainly associated with the exploitation or operation phase of the building. By integrating the principle of deconstruction into the design, the installations are completely freed from the structure, allowing easy and rapid maintenance, replacement, remodeling, updating, etc., at reasonable costs.

The previous reality allows us to accurately characterize the life cycles of the different constituents of the systems and sub-systems (major equipment, networks and minor equipment), by standardizing the technical life cycles of the integrating unit elements. This homologation allows the unitary reuse of parts and pieces, as well as their recycling.

Finally, this conceptual proposal permits life cycle maximization of the reinforced concrete structure. This improves the Sustainability of its Construction by allowing for the renewal and/or complete updating of systems and subsystems, without sacrificing the life cycle of the structure, which is categorically superior to the life cycles of other systems.

\section{Conclusions}

The practical verification of the proposal benefits, theoretically outlined in many publications, will allow us to lead the local, and probably regional market in the area of Construction Sustainability and to become a benchmark project. On the other hand, the theoretical basis of "Lean Construction" can be improved by demonstrating that there is a real parallel between the assembly line of a car and that of a building. Under the concepts of the present proposal, achieving construction without losses and creating an effective bridge between the Lean Construction and the OBS (Open Building System) is possible. Finally, if this proposal is properly disseminated, a radical change will be generated in the supply market for construction materials, in which the large retail chains will probably assume leadership, considering that they already have a peripheral network of installers of all kinds.

\section{References}

Binggelli, C. (2016). Buildings Systems for Interior Designers. Third Edition. Published by John Wiley \& Sons, Inc., Hoboken, New Jersey.

Buxton, P. (2015). Metric Handbook Planning and Design Data. Fifth Edition. Routledge 2 Park Square, Milton Park, Abingdon, Oxon OX14 4RN. Routledge is an imprint of the Taylor \& Francis Group. A business inform.

CIB. (2010). 16thInternational Conference on "Open and Sustainable Building" Proceedings of the international conference jointly organized byCIB W104 - Open Building Implementation and TECNALIA. Bilbao, Spain. May 17-19.

CIB. (2012). Proceedings of the CIB IAARC W119 CIC 2012 Workshop: Advanced Construction and Building Technology for Society. CIB Publication 367.

CIB. (2013). Research Roadmap Report. Off-site Production and Manufacturing. CIB Publication 372.

CIB. (2014). Open Building Implementation. W104 Durban 2014 Proceedings. CIB Publication 400.

Durmisevic, E \& Van lersel (2003). Life cycle Coordination of Materials and their functions at connections design for total service life. In Deconstruction and Materials Reuse CIB Publication 287, page 285-294.

Emmit, S. \& Gorse, C. (2014). Barry's Advanced Construction of Buildings. Third edition by John Wiley \& Sons, Ltd.

Fukao, S. (2009). The History of Developments toward Open Building in Japan. Available online at: https://www.irbnet.de/daten/iconda/CIB11014.pdf

Green, B. (2016). Productivity in Construction: creating a framework for the industry to thrive. Chartered Institute of Building (CIOB). UK. Available online at: https://policy.ciob.org/research/productivity-construction-creating-framework-industry-thrive/

Habraken, N. (1961). Supports an alternative to mass housing, London 1972, Amsterdam 1961 (Dutch version). 
Halliday, S. (2008). Sustainable Construction. Butterworth-Heinemann is an imprint of Elsevier Linacre House, Jordan Hill, and Oxford OX2 8DP, UK.

Haselbach, (2010). The Engineering. Guide to LEED. New Construction Sustainable. Construction for Engineers. Second Edition. McGraw-Hill.

ICC. (2015). International Code Council. Available online at: http://shop.iccsafe.org/codes/2015-internationalcodes-and-references.html

Jünemann, R. (2016). Response of reinforced concrete shear wall buildings during the 2010, Chile earthquake. Doctoral thesis. Pontificia Universidad Católica de Chile.

Kazi, A; Hannus, M; \& Boudjabeur, S. (2009). Open Building Manufacturing Key Technologies, Applications, and Industrial Cases. Published by: ManuBuild.

Lee, Q. (1997). Facilities and Workplace Design. An Illustrated Guide. Engineering \& Management Press. Institute of Industrial Engineers.

Mckinsey Global Institute. (2017). Reinventing construction: A route to higher Productivity. Copyright (C) McKinsey \& Company.

Moscow, K. (2008). Sustainable Facilities. Green Design, Construction, and Operations. McGraw-Hill eBooks.

Okamoto, S.; Ozaki, M.; Hayasi, M.; Yasiro, T.; Nakamura, K.; Matute, M.; Tanaka, Y; \& Gu, J. (2000). Earthquake safety assessment of proposed open building system with target service life of 200 years. Central Research Institute for Construction Technology.

Serpell, A.; Kort, J.; \& Vera, S. (2013). Awareness, actions, drivers and barriers of sustainable construction in Chile. Technological and Economic Development of Economy, 19, 272-288.

Siew Goh, C. \& Rowlinson, S. (2013). Conceptual Maturity Model for Sustainable Construction. Journal of legal affairs and dispute resolution in engineering and construction (C) ASCE / November 2013.

Smith, R. (2010). Prefab Architecture. A guide to modular design and construction. John Wiley \& Sons, Inc., Hoboken, New Jersey.

Vásquez, J. (2015). Nonlinear Modeling of reinforced concrete shear walls using an improved fiber element. Master Thesis. Pontificia Universidad Católica de Chile. 